\title{
Southern Ocean convection shutdown controls potential for long-term climate warming by greenhouse gases
}

Ada Gjermundsen ( $\nabla$ ada.gjermundsen@met.no)

Norwegian Meteorological Institute https://orcid.org/0000-0002-2053-4689

Aleksi Nummelin

NORCE Norwegian Research Centre AS and Bjerknes Centre for Climate Research, Norway

D. Olivié

Norwegian Meteorological Institute, Oslo

\section{Mats Bentsen}

NORCE Climate and Bjerknes Centre for Climate Research https://orcid.org/0000-0001-5441-4063

Øyvind Seland

Norwegian Meteorological Institute

Michael Schulz

Norwegian Meteorological Institute https://orcid.org/0000-0003-4493-4158

\section{Article}

Keywords: climate science, effective climate sensitivity, cloud feedback, CESM2, NorESM2

Posted Date: April 3rd, 2021

DOl: https://doi.org/10.21203/rs.3.rs-361384/v1

License: (9) (i) This work is licensed under a Creative Commons Attribution 4.0 International License.

Read Full License 


\title{
Southern Ocean convection shutdown controls potential for long-term climate warming by greenhouse gases
}

\author{
Ada Gjermundsen ${ }^{1 *}$, Aleksi Nummelin ${ }^{2}$, Dirk Olivié ${ }^{1}$, Mats Bentsen $^{2}, \varnothing_{\text {yvind Seland }}{ }^{1} \&$ Michael \\ Schulz ${ }^{1,3}$ \\ ${ }^{1}$ Norwegian Meteorological Institute, Oslo, Norway \\ ${ }^{2}$ NORCE Norwegian Research Centre AS and Bjerknes Centre for Climate Research, Bergen, \\ Norway \\ ${ }^{3}$ University of Oslo, Department of Geosciences, Oslo, Norway \\ *e-mail:ada.gjermundsen@met.no
}

The effective climate sensitivity (EffCS) estimates the equilibrium near-surface temperature increase due to an doubling of the atmospheric carbon dioxide concentration, and is a widely used metric to characterise potential global warming. Cloud feedback, with considerable contribution from marine boundary layer clouds over the Southern Ocean (SO), has been identified as the main source to the spread and the increase in EffCS in the Earth System Models participating in phase 6 of the Coupled Model Intercomparison Project (CMIP6). We trace the difference in EffCS between the Community Earth System Model (CESM2, EffCS of 5.3K) and the Norwegian Earth System model (NorESM2; EffCS of $2.5 \mathrm{~K}$ ), to SO circulation response. NorESM2 stores more heat at depth than CESM2, which delays the SO surface warming, $S O$ cloud response, and ultimately the global surface warming by centuries in comparison to CESM2. The link between SO and EffCS is seen across 41 CMIP6 models; those with a low EffCS exhibit substantial deep SO warming. The observed slow surface but fast subsurface SO warming supports the notion of SO control over EffCS.

The Earth's climate response to increased atmospheric greenhouse gas (GHG) concentrations needs to be quantified as accurately as possible in order to help plan and execute effective mitigation and adaptation measures. The equilibrium climate sensitivity (ECS) is defined as the global mean surface warming to a doubling of atmospheric carbon dioxide $\left(\mathrm{CO}_{2}\right)$ concentration at the new equilibrium state and involves complex interactions of radiative forcing and feedbacks which can either dampen or amplify the GHG-induced warming. Assuming that the external forcing and the feedback processes remain constant in time, the ECS is generally estimated by the extrapolation of surface temperature trends from 150 years long Earth system model simulations forced by a quadrupling of the atmospheric $\mathrm{CO}_{2}$ concentration (abrupt- $4 \times \mathrm{CO}_{2}$ ) and these estimates are referred to as the "effective climate sensitivity" (EffCS) ${ }^{1 / 3}$. The EffCS usually underestimates the ECS obtained if the models were run to a new equilibrium state ${ }^{4}$. However, EffCS values calculated by this regression method are useful and practical estimates obtainable within the limitation of computing resources and are commonly used e.g. in the scientific literature ${ }^{5 / 7}$ and the Intergovernmental Panel on Climate Change (IPCC) assessment reports.

Cloud feedbacks have a crucial impact on EffCS (and ECS), as positive low cloud feedbacks favour 
high EffCS $^{8-10}$ and differences in total cloud feedback and the shortwave (SW) cloud feedback component are the primary causes for the large intermodel spread in EffCS from phases 3, 5 and 6 of the Coupled Model Intercomparison Project (CMIP) 7]11, 13. Clouds substantially cool the climate $\left(-18 \mathrm{~W} / \mathrm{m}^{2}\right.$; global-mean net effect) as they reflect more solar radiation back to space $\left(-45 \mathrm{~W} / \mathrm{m}^{2}\right.$; an albedo effect) than they emit longwave radiation back towards the surface $\left(27 \mathrm{~W} / \mathrm{m}^{2}\right.$; a greenhouse effect) ${ }^{14}$. The radiative effect of clouds heavily depends on cloud altitude, amount, and optical thickness 15 . Changes in these cloud properties can potentially have large radiative impacts. An interaction between the ocean and the clouds is likely linked to the low cloud cover (LCC) over oceans, which has a large negative radiative effect due to high albedo and weak greenhouse effect ${ }^{16}$. A decrease in the LCC amplifies positive forcing and hence global warming. LCC itself is primarily controlled by two factors, i.e. the inversion strength of the marine planetary boundary layer (PBL) and the sea surface temperature (SST) acts to increase the LCC, implying a negative feedback, as less of the moist PBL air is mixed with the dry free-troposphere air aloft. However, increased SSTs tend to reduce the LCC due to PBL drying and hence act as a positive feedback. Another potentially important cloud feedback, particularly over the Southern Ocean (SO), involves the warming-induced deglaciation of mixedphase mid-level clouds, which increases cloud albedo and acts as a negative feedback. However, this feedback is important only as long as there are enough ice cloud particles present $15,22+26$. The magnitude and sign of the overall cloud feedback depends strongly on the relative strength of these processes.

Cloud feedbacks, with primarily contribution from the marine SO LCC, have been identified as the main source to the spread and the extensive warming in the CMIP6 ensemble $e^{7 / 27 \mid 28}$ due to a substantially more positive cloud feedback in CMIP6 compared to CMIP5 (also see Supplement Fig. 1). The main contribution is from an increase in the southern hemisphere (SH) extratropical SW low cloud component and is due to a larger reduction in LCC and a weaker increase in cloud liquid water path with warming in CMIP6, compared to CMIP57 ${ }^{7}$. The large positive cloud feedback allows for several CMIP6 models to achieve very high EffCS (Fig. 1a). In CMIP5, differences in the tropical Pacific warm-pool warming ratio can account for a large fraction of the increase in EffCS in time ${ }^{529}$, but not in CMIP6 where the SH extratropics seems more dominant and the delayed SO warming relative to the global warming cause a stronger SST pattern effect on the cloud feedback $^{29}$. Due to the sensitivity of LCC to SST changes, the correlation of EffCS to SO SST warming is more profound in CMIP6 $\left(r^{2}=0.83\right)$ compared to the previous phase, CMIP5 $\left(r^{2}=0.29\right)$ (Supplement Fig. 1b). In CMIP6 in models with higher SSTs south of $35^{\circ} \mathrm{S}$, the SW cloud feedback in the corresponding region becomes more positive and contributes to further warming $\left(r^{2}=0.71\right)$, but the relationship does not hold for the CMIP5 models $\left(r^{2}=0.03\right)$, reflecting updated and modified model representations of clouds 7/27/28 (Fig. 1b). However, SST warming is intimately connected to the ocean circulation and mixing processes which control how efficiently heat is transferred from the upper ocean into the deep ocean ${ }^{3031}$ (Fig. 1c). The orange line in Fig. 1c shows the linear regression with a $r^{2}$ of 0.59 . When the two outlier models exhibiting nearly no change in the deep ocean temperatures are excluded (INM-CM4-8 and GISS-E2-H-1), $r^{2}$ increases to 0.80 (grey line), explaining thus a considerable fraction of the spread in the SO SST warming and hence the EffCS 
variability. Further, the deep ocean warming is connected to the deep water formation and hence the weakening in the downwelling branch of the global meridional overturning circulation (MOC) (Fig. 1d).

The CMIP6 models show a connection between deep SO warming and EffCS which was not present in CMIP5 (Supplement Fig. 1a). Models with profound warming in the deep SO tend to have a low EffCS, whereas models that warm only close to the surface exhibit a high EffCS with a $r^{2}$ of 0.35 . When the two outlier models exhibiting nearly no change are excluded (INMCM4-8 and GISS-E2-H-1), $r^{2}$ increases to 0.59. Other models have demonstrated similar ocean temperature response dependence on the pre-industrial base state of the $\mathrm{SO}^{32,33}$.

The ocean heat uptake (OHU) and high-altitude $\mathrm{OHU}$ in particular, is known to have a strong influence on the global mean surface warming rate and anomalous northward ocean heat transport (OHT) in response to GHG forcing can delay SO SST warming 34 37. Increased OHU does not necessarily require circulation changes, as more heat becomes available when the SSTs warm in response to the positive cloud feedback in the same region ${ }^{38}$. However, we show that it is crucial to consider how the up-taken heat is distributed in the water column through ocean circulation and mixing processes. If the poleward SO oceanic eddy-induced heat transport is suppressed subsurface in response to surface freshening, the SO surface warming is weak, which by interaction with the atmosphere has a profound impact on the sign, onset and evolution of the cloud feedback strength and hence EffCS. Thus, the amount of surface suppression of the up-taken heat contributes in large part to the discrepancy between the EffCS calculated by the Gregory regression ${ }^{2 \sqrt{3}}$ using the first 150 years of model simulations, and the ECS. To further explain the mechanisms causing the correlations depicted in Fig. 1, we utilise two members in the CMIP6 ensemble.

\section{The case of CESM2 and NorESM2}

Two members of the CMIP6 model ensemble provide a unique opportunity to gain more insight, i.e. the Community Earth System Model version 2 (CESM2 ${ }^{39}$ ) which is a high-EffCS model $(5.3 \mathrm{~K})^{40}$ and the CESM2-based Norwegian Earth System model version 2 (NorESM2 ${ }^{41}$ ) which is a low-EffCS model $(2.5 \mathrm{~K})$. The major difference between the two models is the ocean component. CESM2 utilises a level-coordinate ocean model based on Parallel Ocean Program version 2 (POP2 ${ }^{42}$ ) while the NorESM2 ocean component involves an isopycnal coordinate model: the Bergen Layered Ocean Model $\left(\mathrm{BLOM}^{43}\right)$. However, the two models share to a large degree the same description for the atmosphere, land and sea ice. The dynamical core in the atmosphere, planetary boundary layer treatment, shallow and deep convection, cloud macrophysics, cloud microphysics and radiation in CESM2 are shared with only small modifications by NorESM2. Aerosol parameterisations are different, but any feedback process involving the pre-industrial aerosol radiative effect is very small and thus not affecting the abrupt- $4 \times \mathrm{CO}_{2}$ experiments, used to derive EffCS. Our experiments in NorESM2 show further that its low EffCS does not depend on changing the atmospheric spatial resolution from nominal $2^{\circ}$ to $1^{\circ}$. The fact that the three models (CESM2, 

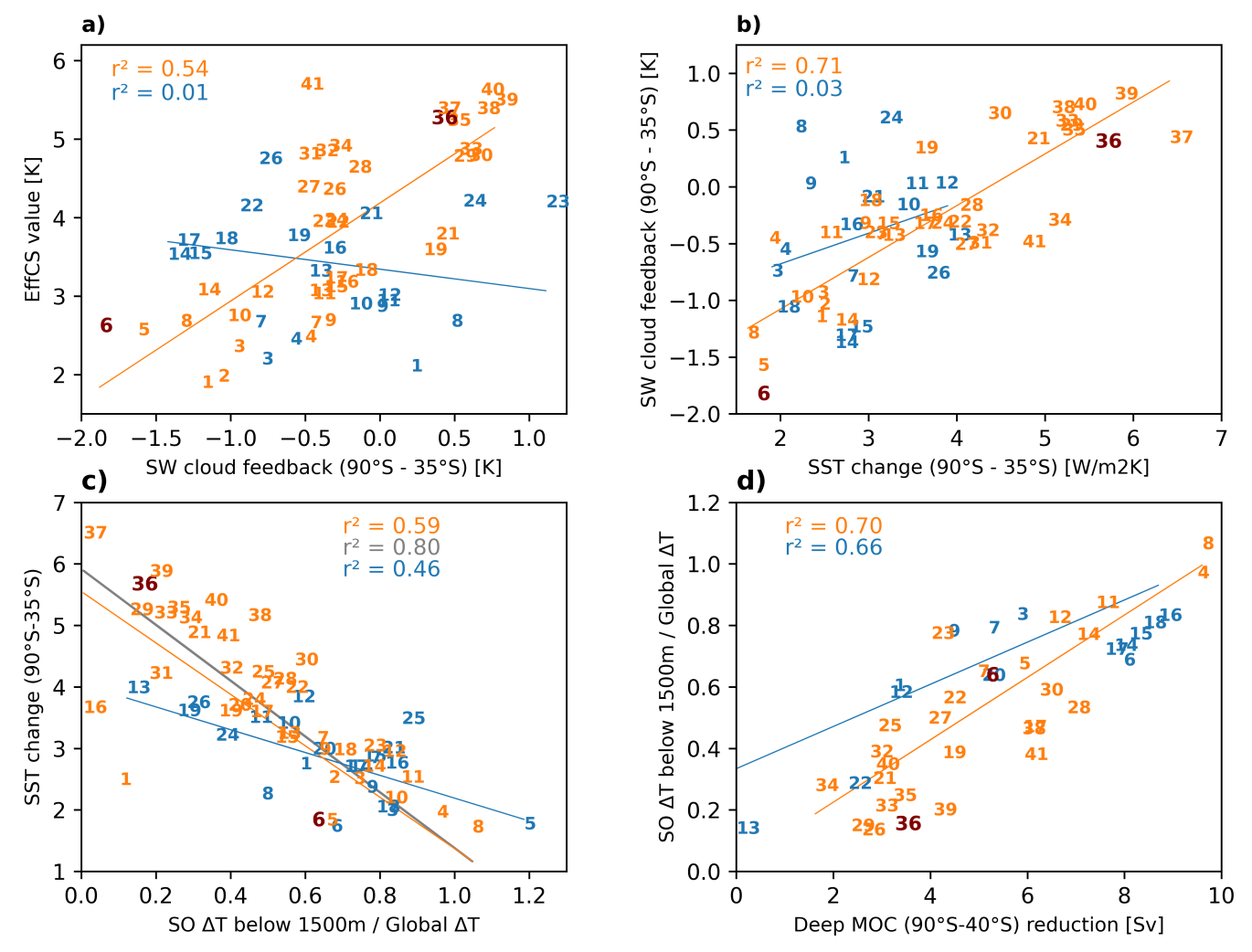

Figure 1: Correlations. Correlations applied to the CMIP5 ensemble (blue) and CMIP6 ensemble (orange). Upper row: EffCS and the SW cloud feedback south of $35^{\circ} \mathrm{S}$ (a), SW cloud feedback and SST warming south of $35^{\circ} \mathrm{S}(\mathbf{b})$, SST warming south of $35^{\circ} \mathrm{S}$ and the change in SO ocean temperature below $1500 \mathrm{~m}$ and south of $50^{\circ} \mathrm{S}$ relative to the change in the global ocean temperature (c), mean reduction in deep MOC south of $40^{\circ} \mathrm{S}$ and the change in SO ocean temperature below $1500 \mathrm{~m}$ and south of $50^{\circ} \mathrm{S}$ relative to the change in the global ocean temperature (d). The two CMIP6 members CESM2 (no. 36) and NorESM2-LM (no. 6) are highlighted in maroon. All models including model numbers and values are listed in Tables 3 and 4 in the supplements. 
NorESM2-LM and NorESM2-MM) are very similar except for their ocean component has been verified in forced SST experiments. Forced with uniformly increased SSTs $(+4 \mathrm{~K})$, they all show an atmospheric feedback factor of $-0.8 \mathrm{Wm}^{-2} \mathrm{~K}^{-1}$, and forced with $4 \times \mathrm{CO}_{2}$ and using the same preindustrial SST, they show very similar effective $\mathrm{CO}_{2}$ radiative forcings of $8.63 \mathrm{Wm}^{-2}$ (CESM2), $8.39 \mathrm{Wm}^{-2}$ (NorESM2-MM), and 8.23Wm ${ }^{-2}$ (NorESM2-LM) (see Supplement Tables 1 and 2 for further details).

The strong influence of the ocean component on the total feedback factor and hence the EffCS, is seen in the fully coupled abrupt- $4 \times \mathrm{CO}_{2}$ simulations, for which NorESM2 $\left(-1.4 \mathrm{Wm}^{-2} \mathrm{~K}^{-1}\right)$ exhibits more than twice the value of CESM2 $\left(-0.6 \mathrm{Wm}^{-2} \mathrm{~K}^{-1}\right)$ when the first 150 years are considered. However, after 500 years the global mean surface temperature warming in NorESM2 reaches $3.4 \mathrm{~K}$ (Fig. 2c), already well above the estimated EffCS value of $2.5 \mathrm{~K}^{7 / 41}$. When the models are run longer, it appears that NorESM2 and CESM2 both exhibit a high ECS. Apparently, the warming trend in the first 150 years is not representative for the warming in an equilibrium state in NorESM2. This confirms that ECS values from millennial-length simulations are generally higher than the values obtained by the aforementioned regression method ${ }^{4}$. Applying the regression method fit to the years $21-500^{5}$, the resulting EffCS values increase by nearly $5 \mathrm{~K}$ to 7.2 K for NorESM2, and to 6.5 K for CESM2 (Supplement Fig. 3). These values are probably closer to the correct ECS values obtained if the models were run to equilibrium.

Both models exhibit a reasonable historic warming, with a tendency of the CESM2 for larger warming, in accordance with its higher EffCS. Given the importance of the cloud feedbacks for the EffCS, we hypothesise that the interaction between the ocean and the clouds plays a crucial role in climate evolution under enhanced GHG concentration levels.

\section{Feedbacks and short wave cloud feedback}

Estimates of the radiative feedbacks show that CESM2 and NorESM2 exhibit similar feedbacks for most components except for the SW cloud feedback which dominates the discrepancy in both magnitude and time evolution (Fig. 2). The increase over time in the SW cloud feedback dominates the temporal evolution of the net feedback in NorESM2 (Supplementary Fig. 5f) over the first 150 years and explains the considerably lower EffCS than ECS in NorESM2.

For the first 150 years of the simulations, CESM2 exhibits a SW cloud feedback approximately $0.5 \mathrm{~W} / \mathrm{m}^{2} / \mathrm{K}$ larger than NorESM2 (Fig. 2b) and this is reflected in the global mean surface warming (Fig. 2c) where CESM2 shows a significantly warmer climate than NorESM2. The SW cloud feedback regressed on near-surface temperature suggests that CESM2 and NorESM2 exhibit similar SW cloud feedback when the global surface temperature increase exceeds $5 \mathrm{~K}$ warming (Fig. 2d), consistent with the results from our fixed SST simulations. However, the SW cloud feedbacks are not identical for the same amount of warming, which might be the impact of the pattern of SST warming. Altogether, CESM2 warms rather rapidly and reaches a $5 \mathrm{~K}$ warming within 30 years, while a similar warming takes NorESM2 more than 200 years. 

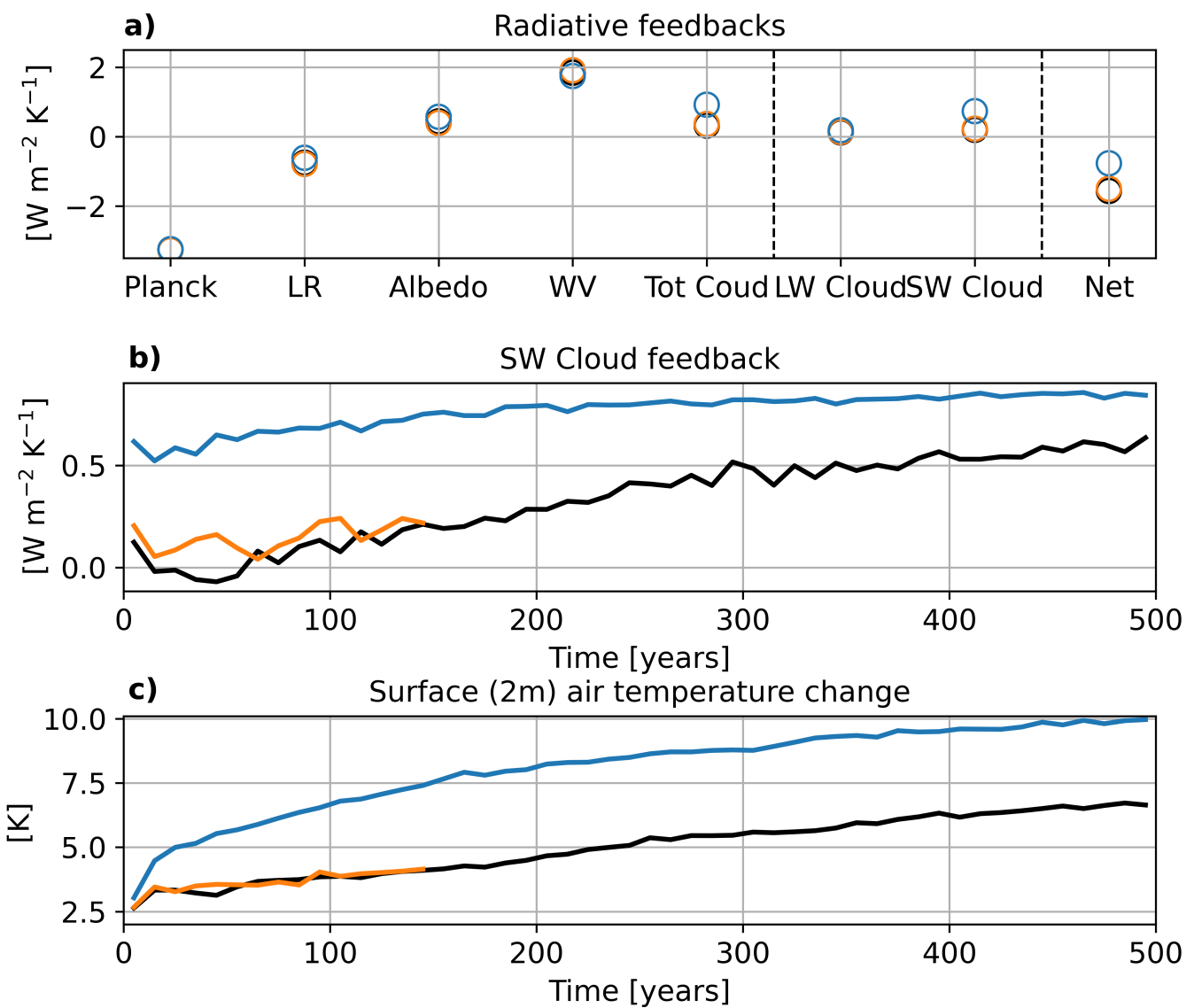

d) SW Cloud feedback

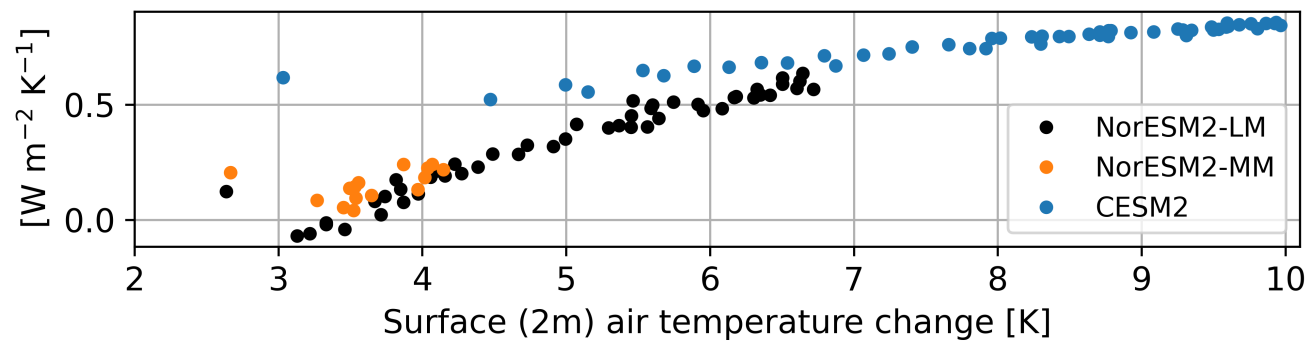

Figure 2: Radiative feedbacks. Estimates of radiative feedbacks for NorESM2-LM (black), NorESM2-MM (orange) and CESM2 (blue) calculated from abrupt- $4 \times \mathrm{CO}_{2}$ GHG-forcing simulations. The total feedback is broken down into Planck, lapse rate (LR), surface albedo, water vapour (WV) and cloud feedbacks. The cloud feedback is further broken down in contributions from SW and LW components (a). Evolution of SW cloud feedback (b) and near surface ( $2 \mathrm{~m})$ temperature change (c) as a function of time, and evolution of SW cloud feedback as a function of the near surface $(2 \mathrm{~m})$ air temperature change $(\mathbf{d})$. 


\section{Sea surface warming and cloud response}

The initial SO (south of $35^{\circ} \mathrm{S}$ ) SST warming, and hence the onset of a more positive cloud feedback, is delayed in NorESM2 compared to CESM2 (Fig. 3). In CESM2, the SO SSTs warm rapidly, whereas in NorESM2 the SST warming is weak and regions within Weddell Sea and northern Ross Sea even cool down in the first 150 years. In these regions, the pre-industrial control simulation of NorESM2 exhibits very deep ocean convection and profound deep-water formation. Only after 500 years is the SST warming pattern and magnitude in NorESM2 comparable to that after 150 years in CESM2 (Fig. 3c,d, Supplement Fig. 6)

As the SSTs warm, CESM2 exhibits a profound decrease in the low and mid-level cloud cover south of $35^{\circ} \mathrm{S}$ (Fig. 3a,c). In response to the slow NorESM2 warming, the low and mid-level clouds south of $35^{\circ} \mathrm{S}$ hardly change at all in the first 150 years. From the start there is a slight increase in LCC suggesting that a warming-induced increase in inversion strength may dominate the effect of SST warming. This increase in LCC in the abrupt- $4 \times \mathrm{CO}_{2}$ relative to the pre-industrial control experiment persists for nearly 500 years in NorESM2.

The LCC response is reflected in the zonally averaged SW cloud feedback (Fig. 3e,f) and is especially evident south of $35^{\circ} \mathrm{S}$ where NorESM2 exhibits a profound negative SW cloud feedback after 150 years, while the SW cloud feedback in CESM2 is at that time mainly positive (Fig. 3e). The abundance of oceanic low and mid-level clouds in this region has a large radiative effect due to the high albedo ${ }^{16}$ and even a slight increase in LCC will contribute to the net negative SW cloud feedback. In addition, the increase in albedo as a result of deglaciation of mixed-phase clouds contributes to the net feedback ${ }^{26}$. Most interestingly, when NorESM2 eventually warms after 500 years, the SW cloud feedback south of $35^{\circ} \mathrm{S}$ resembles that of CESM2 (Fig. 3f) confirming the results from aforementioned fixed SST experiments.

\section{Ocean mechanisms responsible for delayed SO surface warming}

The SO dominates the net global ocean uptake of excess heat from the atmosphere, and this OHU delays the Earth's surface temperature response to anthropogenic GHG forcing ${ }^{31 / 44}$. The high OHU in the SO is due to the mean SO circulation which in the Deacon cell moves heat northwards and downwards ${ }^{30}$ : strong westerlies drive an upwelling of cold water masses along steeply tilted isopycnals (surfaces of constant potential density) from depth over the Antarctic Circumpolar Current (ACC), Ekman transport moves the cold waters northward, and surface fluxes warm the waters before they subduct in the interior along the polar front. Mesoscale eddies, on the contrary, move heat southward and from mid-depth to the surface across the ACC ${ }^{30 \mid 45}$. The net overturning circulation from the mean circulation and the eddy-induced circulation, make up the upper meridional overturning circulation (MOC) cell in the SO which is responsible for most of the heat uptake. The lower SO MOC cell, the Antarctic Bottom Water (AABW) cell, is fed by deep water primarily formed by convection processes in the Weddell and Ross Seas.

In CESM2, stronger westerlies drive a more intense and deeper upper SO MOC cell compared to 

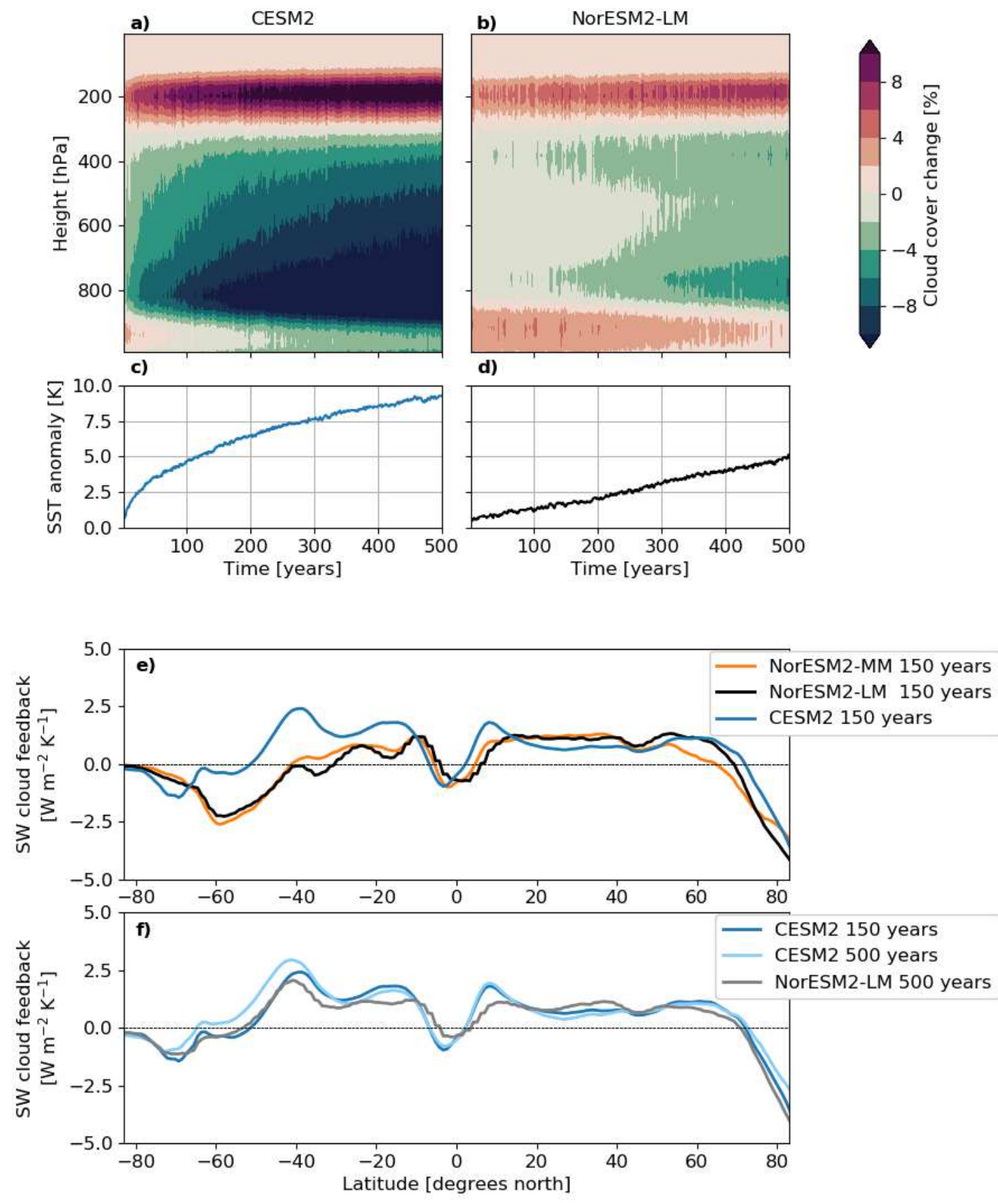

Figure 3: Cloud changes, SST warming and SW cloud feedback. Time evolution of cloud cover fraction anomaly averaged south of $35^{\circ} \mathrm{S}$ for CESM2 (a) and NorESM2-LM (b) for the first 500 years. SST anomaly for the same region and time as in a-b for CESM2 (c) and NorESM2-LM (d). Zonally averaged SW cloud feedback in NorESM2-MM (orange), NorESM2-LM (black) and CESM2 (blue) after 150 years (e) and after 500 years in NorESM2-LM (grey), and CESM2 (light blue) (f). Also included in (f) is the SW cloud feedback from CESM2 (blue) after 150 years for comparison. 
NorESM2 (Supplementary Fig. 7). The larger wind stress forcing is reflected in deeper isopycnals throughout the latitudes of ACC and colder water masses above the pycnocline (Supplementary Figs. 7-10). In the far south, poleward of $60^{\circ} \mathrm{S}$, the higher stratification in the upper $500 \mathrm{~m}$ is maintained by eddy transport of warm North Atlantic Deep Water (NADW) to the surface. In NorESM2, the potential density structure differs substantially from that of CESM2, with very weak stratification close to Antarctica. Extensive areas of persistent open water in sea-ice regions, socalled open ocean polynyas, persist for all years outside Weddell Sea and for some years outside Ross Sea in the pre-industrial simulation of NorESM2 in both resolutions. The polynyas cause very deep convection reaching all the way to the bottom and vigorous AABW formation. This is reflected in the strength of the deep AABW cell which is 5 times stronger in NorESM2 (-12.7 Sv) than in CESM2 (-2.5 Sv) and a much colder abyssal ocean in NorESM2.

The future SO OHU is projected to increase under global warming ${ }^{31 / 44}$ due to intensification of the downward heat transport by the mean flow and/or a weakening of the eddy-induced upward heat transport. These changes will drive subsurface warming in the SO in response to GHG forcing ${ }^{30 \mid 46}$, but the amount and at which depth the warming takes place, is highly model dependen ${ }^{44}$ as revealed when comparing CESM2 and NorESM2.

Except for colder surface waters in the SO, CESM2 exhibits a warmer ocean than NorESM2 in the pre-industrial control. Forced by abrupt- $4 \times \mathrm{CO}_{2}$, the SO surface winds strengthen causing the base state ocean circulation and the SO MOC in particular, to intensify. The eddy-induced MOC strengthens at the polar front, primarily close to the surface (shading Fig. 4d). As the SSTs warm in response to GHG forcing and the cloud feedbacks, the OHU in the SO increases. Importantly, the isopycnal slopes are maintained throughout the simulation and hence the circulation which brings warm subsurface water to the surface in CESM2 persists (indicated by black arrows in Fig. 4d), causing the ocean warming in CESM2 to be surface intensified (red contour in Fig. 4d).

In NorESM2, the response is different. In the pre-industrial state the SO isopycnal structure in NorESM2 is strongly influenced by the vigorous convection. Persistent polynyas in the preindustrial simulation require eddy transport of heat from the subsurface ocean to the surface to prevent formation of sea-ice. The heat is absorbed by the cold winter atmosphere and effectively emitted to space, which cools the ocean surface and hence maintain deep convection in the polynya regions. An abrupt $-4 \times \mathrm{CO}_{2}$ forcing shuts down the deep convection in NorESM2 within a few years due to a positive buoyancy input from the melting sea ice. As the convection stops the isopycnals deepen south of $60^{\circ}$ (Fig. 4e) and the along isopycnal transport is no longer connected to the surface (black arrows in Fig. 4e). In addition to at the surface strengthening of the eddyinduced MOC (similar to the response in CESM2), NorESM2 exhibits an intensification in the eddy-induced MOC at depth, with a maximum at $900 \mathrm{~m}$ (shading Fig. 4d). Consequently, the the (parameterized) poleward eddy-induced heat transport intensifies subsurface, causing warming at depth (red contour in Fig. 4e) and cooling at the surface $30,47,49$. 
The different ocean responses cause a large discrepancy in the SO warming seen in CESM2 and NorESM2. In NorESM2 the entire ocean column warms in response to the abrupt- $4 \times \mathrm{CO}_{2}$ forcing (Fig. 4a). On the contrary, the heat is trapped in the upper ocean in CESM2 which triggers a positive SW cloud feedback almost immediately (Figs. 2e, 4). This striking difference in the vertical redistribution of heat in CESM2 and NorESM2 is clearly evident after 500 years (Fig. 4b,c). There is actually a reduction in the ocean heat content (OHC) below $2000 \mathrm{~m}$ in the first 380 years in CESM2 (Supplementary Fig. 12), suggesting a reduced and shallower overturning circulation in the Atlantic that dominates the ocean response to the GHG-induced warming. In NorESM2, the OHC below $2000 \mathrm{~m}$ increases reflecting a shutdown of the SO convection.

\section{Convection shutdown sensitivity study}

To further investigate the role of convection shutdown in the abrupt- $4 \times \mathrm{CO}_{2}$ experiments, we study its impact on the SSTs without additional GHG forcing in NorESM2. To do so we enhance the freshwater input to the Weddell Sea and the surrounding area (see black, dashed line in Fig. 4f) in a pre-industrial simulation. The freshwater forcing efficiently reduces the deep convection in this region and the isopycnal response resembles that of the abrupt- $4 \times \mathrm{CO}_{2}$ experiment. Over the first 5 years SSTs cool over a much larger region than the regions where deep convection occurs and where the freshwater forcing was applied (Fig. 4f). The cooling, which extends to $30^{\circ} \mathrm{S}$, is due to a reorganisation of the water masses in response to the convection shutdown as the timescale is too short for the response to be a consequence of solely advection. The regions of cooling are overlapping with the regions of negative SW cloud feedback (indicated by grey, dotted lines in Fig. 4f-i) in both models. The regions of little warming and cooling in response to abrupt- $4 \times \mathrm{CO}_{2}$ forcing (Fig. 4g) resemble those where the SST response to convection shutdown is appearing (Fig. 4f). When the SST response to the convection shutdown is removed from the abrupt- $4 \times \mathrm{CO}_{2}$ response (Fig. 4h), the SST response is in better agreement with CESM2 (Fig. 4i).

\section{Observed and simulated SO SST warming}

While most of the Earth's surface has been warming, the SO has experienced cooling at the surface over the recent historical period (Fig. 4j); a trend that has been difficult to reproduce in coupled climate models. The surface cooling has been linked to mainly two mechanisms: a poleward shift in the atmospheric jet changing the Ekman dynamics (equatorward transport at the surface ${ }^{50}$ and upwelling of previous winter water along the sea-ice edge ${ }^{51}$ ) and a reduced upwelling of the warm intermediate waters due to surface freshening 52 . Most recently, surface freshening has been suggested as the main mechanism to explain the cooling as it also explains the observed warming at the subsurface 52 53, although the mechanism for the observed freshening remains elusive (northward sea ice transport 52, increased net precipitation ${ }^{54}$, increased glacial melt ${ }^{55}$ ). Even if the observed and simulated mechanisms might differ and the vigorous pre-industrial SO deep convection in NorESM2 is more excessive than observations suggest ${ }^{56}$, the historical SST trends are better captured in NorESM2 than in CESM2 (Fig. 4k-m), which could indicate that the oceanic control on the cloud feedback seen in NorESM2 is realistic. This is also supported by Zhang et al. $2019^{57}$ who found that the SO convection state controls the decadal predictability. 


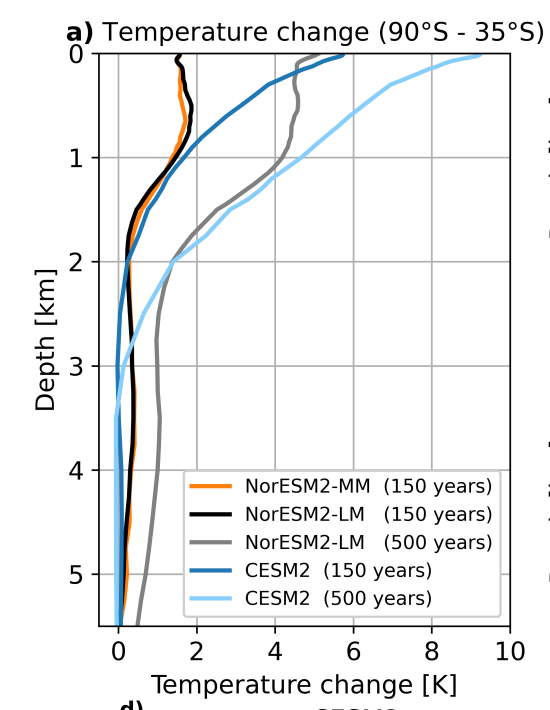

b) NorESM2-LM (500 years)

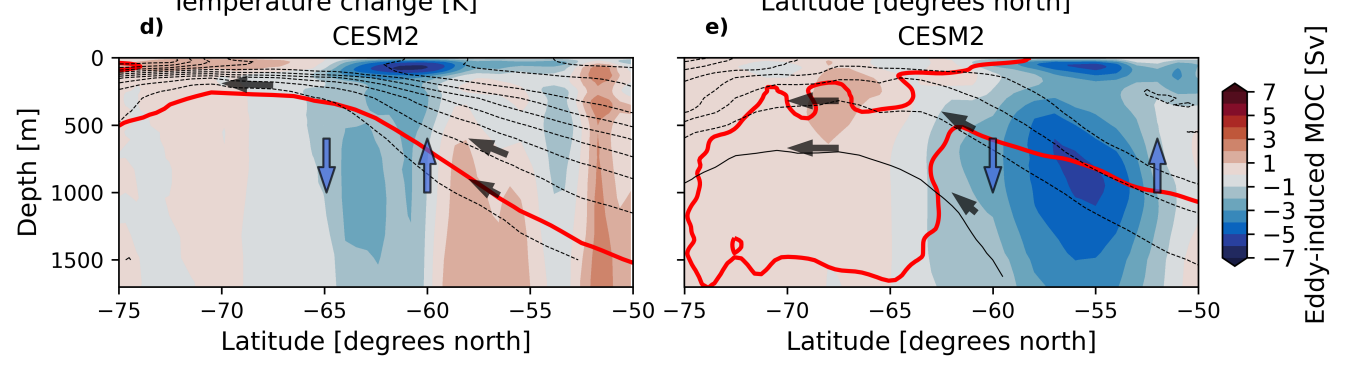

Initial SST warming (1-5 years)
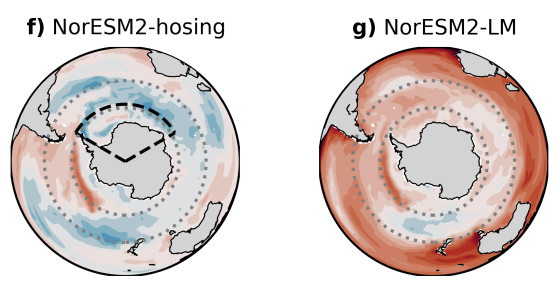

h) NorESM2-LM - NorESM2-hosing
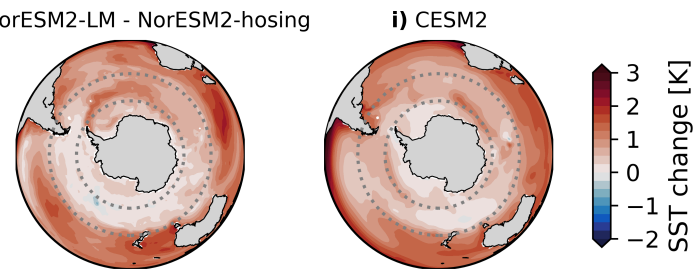

Historical SST trends (1960 - 2014)
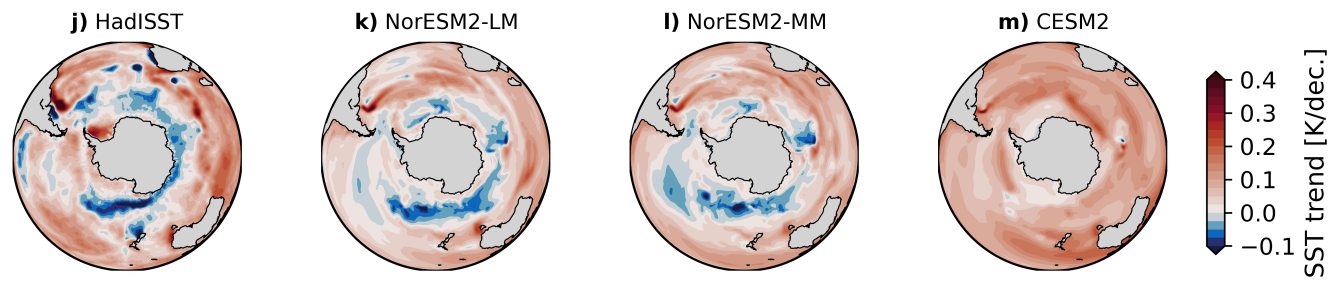

Figure 4: Ocean temperature response. Ocean temperature anomaly averaged south of $35^{\circ} \mathrm{S}$ in NorESM2-MM (orange), NorESM2-LM (black) and CESM2 (blue) after 150 years and after 500 years in NorESM2-LM (grey) and CESM2 (light blue) (a). Zonally averaged ocean temperature anomaly after 500 years in NorESM2-LM (b) and CESM2 (c). Response in the eddy-induced MOC to abrupt $-4 \times \mathrm{CO}_{2}$ forcing after 150 years (shading) and in the surfaces of constant density (black, dashed lines) in CESM2 (d) and NorESM2-LM (e). The black arrows indicate the anomalous along-isopycnal transport and the red contour show the $1 \mathrm{~K}$ warming. The initial (first 5 years) SST response to forcing in NorESM2-LM and CESM2 (g,i). SST anomaly to SO convection shutdown in NorESM2-LM (f). The region of freshwater forcing is indicated by the black dashed lines. SST anomaly to abrupt- $4 \times \mathrm{CO}_{2}$ forcing (f) and to abrupt $-4 \times \mathrm{CO}_{2}$ forcing when the response from the convection shutdown is removed (f subtracted from $\mathbf{g}$ ) (h). SST anomaly to abrupt- $4 \times \mathrm{CO}_{2}$ forcing in CESM2 (i). The grey dotted lines in e-h indicate the region with high negative SW cloud feedback bounded by $62^{\circ} \mathrm{S}$ and $45^{\circ} \mathrm{S}$ (see Fig. 2). SST trends for the period (1960-2014) from observations (HadISST, j), NorESM2-LM (k), NorESM2-MM (l) and CESM2 (m). 


\section{Discussion}

The majority of the CMIP6 models exhibit too large and too frequent open-ocean polynas in the pre-industrial control simulations and most models form the AABW by open-ocean deep convection, but the convection strength and the amount of AABW formation are highly model dependen ${ }^{56}$. Importantly, the state of the pre-industrial control simulation will pre-condition the ocean redistribution of the SO uptaken heat causing different climate responses when forced by a quadrupling of $\mathrm{CO}_{2}$. Our study shows that if the heat taken up in the SO stays subsurface and cause mainly deep ocean warming, the long timescale of the ocean overturning circulation will have a much larger impact on the EffCS estimates due to slow SST warming and hence slow activation of a more positive shortwave cloud feedback. Consequently, for such models the EffCS estimates using 150 years will be low compared to the ECS. Further insights into SO ocean warming patterns, associated cloud changes and model evaluation of the corresponding trends would be required to quantify the climate controlling role of the SO.

Deep OHU has been suggested as a major source of model spread in future warming due to less surface warming ${ }^{58}$. Others have argued that the role of OHU is limited compared to that of climate feedbacks 59 . In several studies, the SO is considered more of a passive sink of heat which dampens the surface warming from the positive cloud feedback $35 / 36 / 38 / 60$. However, our study shows that the ocean response in the CMIP6 models to GHG-forcing can be diverse, and that convection shut down in particular can have a profound effect on SST warming and hence the cloud feedback. Consequently, the spread in SW cloud feedback and the deep ocean warming are not independent sources of uncertainty, but intertwined responses in a coupled system. Models with deep ocean convection are associated with less SST warming under GHG-forcing and thus the SW cloud feedback depends on the base state of the ocean. Specifically, our results show that SO deep convection controls the ocean-atmosphere coupling and is a major contributor to the wide spread of EffCS among CMIP6 models.

\section{Methods}

\section{Fixed SST experiments}

Fixed SST model simulations were conducted and analysed in order to investigate the feedbacks in NorESM2-LM, NorESM2-MM and CESM2 when forced with a) similar sea surface temperature (SST) warming (+4 K) and b) forced by the same GHG forcing $\left(4 \times \mathrm{CO}_{2}\right)$ and observed SSTs. We used Atmospheric Model Intercomparison Project (AMIP) experiments in which the atmosphere and land components were active while values for SSTs and sea ice were prescribed. The values from these experiments are listed in Table 1 and 2 in the supplements.

\section{Radiative feedbacks}

We employ radiative kernels ${ }^{61}$ from Pendergrass et al. $2018^{62}$ calculated with CESM-CAM5 ${ }^{63}$ to quantify the various contributions of radiative feedbacks to the total change in the TOA radiative fluxes. The feedbacks are calculated by multiplying kernels for the atmospheric and surface tem- 
perature, water vapour and surface albedo by the change in the relevant climate variables and then normalised by the change in the global averaged temperature or regionally averaged when only the region south of $35^{\circ} \mathrm{S}$ is considered. The feedbacks due to atmospheric temperature and water vapour are vertically integrated up to a time-varying tropopause ${ }^{64}$. Cloud feedback calculations follow Soden et al. (2008) and are calculated by adjusting the CRE (all-sky minus clear-sky radiation) for non-cloud influences including radiative forcing due to GHG and aerosol ${ }^{62}$. We use 30 years averaged monthly climatology then averaged temporarily and either globally or regionally. Figs. 1,2a show the feedbacks using climatology and anomalies averaged over the last 30 of the 150 years long model simulations and Fig. 2b,d show 10 years averaged values for 500 years (Fig. 2b) and regressed on the globally averaged surface temperature change for the corresponding period (Fig. 2d).

\section{CMIP archive}

We analysed all CMIP5 and CMIP6 models for which the piControl and abrupt- $4 \times \mathrm{CO}_{2}$ experiments with the incoming and reflected shortwave and outgoing longwave radiation at the top of the atmosphere as well as the potential ocean temperature monthly fields were available. Only one piControl and one abrupt $-4 \times \mathrm{CO}_{2}$ experiment with the same realisation number (in most cases r1i1p1f1) per model was considered (see Table 3 and 4 in Supplements for an overview). All CMIP data used is available from the The Earth System Grid Federation (ESGF) server https : //esgf-node.llnl.gov/projects/esgf-llnl, piControl experiments refer to simulations with GHG concentrations and emissions fixed at pre-indutrial 1860 levels. The abrupt$4 \times \mathrm{CO}_{2}$ experiment is identical to the parent experiment, piControl, except for a quadrupling of the atmospheric $\mathrm{CO}_{2}$ concentration.

\section{EffCS}

The EffCS values are calculated using the first 150 years output from CMIP6 models forced with a quadrupling of the atmospheric $\mathrm{CO}_{2}$ concentration relative to pre-industrial levels and the corresponding time period from the pre-industrial control simulation. Anomalies are calculated by subtracting a linear regression of the pre-industrial values to reduce the interannual variability. A linear relationship is assumed between globally- and annually averaged anomalies of surface $(2 \mathrm{~m})$ air temperature and top of the atmosphere (TOA) net downwelling radiation. The EffCS is the temperature for the $\mathrm{x}$-interception (where the net TOA radiation anomaly equals zero) divided by two in order to give the temperature for a doubling of $\mathrm{CO}_{2}$. The EffCS calculations are based on the methods by Gregory et al. 2004 ${ }^{2}$.

\section{CMIP6, SO warming and regression}

The ocean temperature anomalies for CMIP6 models are calculated as the temperature difference between the abrupt $-4 \times \mathrm{CO}_{2}$ simulations and the corresponding pre-industrial control simulation temporarily averaged over the 30 last of the 150 year. The Theil-Sen estimator is used for a robust fitting linear regression. The r-squared values are calculated using a Monte-Carlo sampling of 50.000 subsamples of 10 models and then averaged.

\section{Hosing experiment}


A hosing experiment, NorESM2-HOS5, was conducted to see the impact of the large open-ocean polynya situated north of Weddell Sea on SSTs. An enhanced freshwater input of $0.17 \mathrm{~Sv}$ was applied to the Weddell Sea and the surrounding area bounded by $60^{\circ} \mathrm{S}, 60^{\circ} \mathrm{W}$ and $50^{\circ} \mathrm{E}$ (see black, dashed line in Fig. 4f).

Author contributions All co-authors are part of the NorESM consortium (NCC) that develops the NorESM2 model. A.G. performed the analysis and wrote the manuscript. D.O. conducted and analysed the fixed SST simulations. D.O., Ø.S. and A.G. performed the NorESM2 model simulations. M.B. and A.N. helped with the ocean analysis. All authors helped write the paper and on the interpretation of the results.

Competing financial interests The authors declare that they have no competing financial interests.

Data availability All CMIP6 data used is available from the ESGF server https://esgf-node. llnl.gov/projects/esgf-llnl and was downloaded in February 2020. The data from the hosing experiment, NorESM2-HOS5, used to produce panel f,h in Fig. 4 will be made available through a downloadable link, facilitated by Uninett Sigma (https://www.uninett.no/en/sigma)

Code availability All code used for the analysis can be obtained from the Corresponding Author upon request. The kernels used in the feedback analysis in Fig. 1 and Fig. 3 can be obtained from https:// github.com/apendergrass/cam5-kernels. The CESM2 source code can be accessed at https: //github.com/ESCOMP/CESM. The NorESM2 source code can be accessed from https://github. Com/NorESMhub/NorESM.

Correspondence Correspondence and requests for materials should be addressed to A.G. (email: ada.gjermundsen@met.no).

Acknowledgements This work was supported by the European Framework Programme Horizon 2020 project CRESCENDO (Coordinated Research in Earth Systems and Climate: Experiments, Knowledge, Dissemination and Outreach, grant agreement no. 641816), and by the Norwegian Research Council funded projects INES (270061) and KeyClim (295046). High performance computing and storage resources were provided by UNINETT Sigma2 - the Norwegian infrastructure for computational science.

\section{References}

1. Murphy, J. M. Transient response of the hadley centre coupled ocean-atmosphere model to increasing carbon dioxide. part iii: Analysis of global-mean response using simple models. $J$. Clim. 8, 496 - 514 (1995).

2. Gregory, J. M. et al. A new method for diagnosing radiative forcing and climate sensitivity. Geophys. Res. Let. 31, L03205 (2004).

3. Andrews, T., Gregory, J. M., Webb, M. J. \& Taylor, K. E. Forcing, feedbacks and climate sensitivity in cmip5 coupled atmosphere-ocean climate models. Geophys. Res. Let. 39, L09712 (2012). 
4. Rugenstein, M. et al. Equilibrium climate sensitivity estimated by equilibrating climate models. Geophys. Res. Let. 47, e2019GL083898 (2020).

5. Andrews, T., Gregory, J. M. \& Webb, M. J. The dependence of radiative forcing and feedback on evolving patterns of surface temperature change in climate models. J. Clim. 28, 1630-1648 (2015).

6. Knutti, R., Rugenstein, M. A. \& Hegerl, G. C. Beyond equilibrium climate sensitivity. Nature Geoscience 10, 727-736 (2017).

7. Zelinka, M. D. et al. Causes of higher climate sensitivity in cmip6 models. Geophys. Res. Let. 47, e2019GL085782 (2020).

8. Myers, T. A. \& Norris, J. R. On the relationships between subtropical clouds and meteorology in observations and cmip3 and cmip5 models. J. Clim. 28, 2945-2967 (2015).

9. Myers, T. A. \& Norris, J. R. Reducing the uncertainty in subtropical cloud feedback. Geophys. Res. Let. 43, 2144-2148 (2016).

10. Brient, F. \& Schneider, T. Constraints on climate sensitivity from space-based measurements of low-cloud reflection. J. Clim. 29, 5821-5835 (2016).

11. Bony, S. \& Dufresne, J.-L. Marine boundary layer clouds at the heart of tropical cloud feedback uncertainties in climate models. Geophys. Res. Let. 32, L20806 (2005).

12. Vial, J., Dufresne, J.-L. \& Bony, S. On the interpretation of inter-model spread in cmip5 climate sensitivity estimates. Clim. Dyn. 41, 3339-3362 (2013).

13. Webb, M. J., Lambert, F. H. \& Gregory, J. M. Origins of differences in climate sensitivity, forcing and feedback in climate models. Clim. Dyn. 40, 677-707 (2013).

14. Henderson, D. S., L'Ecuyer, T., Stephens, G., Partain, P. \& Sekiguchi, M. A multisensor perspective on the radiative impacts of clouds and aerosols. J. Appl. Meteorol. Climatol. 52, 853-871 (2013).

15. Ceppi, P., Brient, F., Zelinka, M. D. \& Hartmann, D. L. Cloud feedback mechanisms and their representation in global climate models. Wiley Interdiscip. Rev. Clim. Change 8, e465 (2017).

16. Hartmann, D. L., Ockert-Bell, M. E. \& Michelsen, M. L. The effect of cloud type on earth's energy balance: Global analysis. J. Clim. 5, 1281-1304 (1992).

17. Bretherton, C. S. \& Wyant, M. C. Moisture transport, lower-tropospheric stability, and decoupling of cloud-topped boundary layers. J. Atmos. Sci. 54, 148-167 (1997).

18. Wood, R. \& Bretherton, C. S. On the relationship between stratiform low cloud cover and lower-tropospheric stability. J. Clim. 19, 6425-6432 (2006). 
19. Qu, X., Hall, A., Klein, S. A. \& Caldwell, P. M. On the spread of changes in marine low cloud cover in climate model simulations of the 21st century. Clim. Dyn. 42, 2603-2626 (2014).

20. Qu, X., Hall, A., Klein, S. A. \& DeAngelis, A. M. Positive tropical marine low-cloud cover feedback inferred from cloud-controlling factors. Geophys. Res. Let. 42, 7767-7775 (2015).

21. McCoy, D. T., Eastman, R., Hartmann, D. L. \& Wood, R. The change in low cloud cover in a warmed climate inferred from airs, modis, and era-interim. J. Clim. 30, 3609-3620 (2017).

22. Tsushima, Y. et al. Importance of the mixed-phase cloud distribution in the control climate for assessing the response of clouds to carbon dioxide increase: a multi-model study. Clim. Dyn. 27, 113-126 (2006).

23. Cheng, A., Xu, K.-M., Hu, Y. \& Kato, S. Impact of a cloud thermodynamic phase parameterization based on calipso observations on climate simulation. J. Geophys. Res. 117, D09103 (2012).

24. McCoy, D. T., Hartmann, D. L. \& Grosvenor, D. P. Observed southern ocean cloud properties and shortwave reflection. part ii: Phase changes and low cloud feedback. J. Clim. 27, 88588868 (2014).

25. Tan, I., Storelvmo, T. \& Zelinka, M. D. Observational constraints on mixed-phase clouds imply higher climate sensitivity. Science 352, 224-227 (2016).

26. Bjordal, J., Storelvmo, T., Alterskjær, K. \& Carlsen, T. State-dependent cloud phase feedback makes equilibrium climate sensitivity $>5^{\circ} \mathrm{c}$ plausible. under revision, Nature. Geosci. (2020).

27. Schlund, M., Lauer, A., Gentine, P., Sherwood, S. C. \& Eyring, V. Emergent constraints on equilibrium climate sensitivity in cmip5: do they hold for cmip6? Earth System Dynamics 11, 1233-1258 (2020).

28. Meehl, G. A. et al. Context for interpreting equilibrium climate sensitivity and transient climate response from the cmip6 earth system models. Science Advances 6 (2020).

29. Dong, Y. et al. Intermodel Spread in the Pattern Effect and Its Contribution to Climate Sensitivity in CMIP5 and CMIP6 Models. Journal of Climate 33, 7755-7775 (2020).

30. Gregory, J. M. Vertical heat transports in the ocean and their effect on time-dependent climate change. Clim. Dyn. 16, 501-515 (2000).

31. Armour, K. C., Marshall, J., Scott, J. R., Donohoe, A. \& Newsom, E. R. Southern ocean warming delayed by circumpolar upwelling and equatorward transport. Naturegeo 9, 549-554 (2016).

32. Newsom, E. R., Bitz, C. M., Bryan, F. O., AberNaturehey, R. \& Gent, P. R. Southern ocean deep circulation and heat uptake in a high-resolution climate model. J. Clim. 29, 2597-2619 (2016). 
33. He, J., Winton, M., Vecchi, G., Jia, L. \& Rugenstein, M. Transient climate sensitivity depends on base climate ocean circulation. J. Clim. 30, 1493-1504 (2017).

34. Winton, M., Takahashi, K. \& Held, I. M. Importance of ocean heat uptake efficacy to transient climate change. J. Clim. 23, 2333-2344 (2010).

35. Geoffroy, O. et al. Transient climate response in a two-layer energy-balance model. part i: Analytical solution and parameter calibration using cmip5 aogcm experiments. J. Clim. 26, 1841-1857 (2013).

36. Armour, K. C., Bitz, C. M. \& Roe, G. H. Time-varying climate sensitivity from regional feedbacks. J. Clim. 26, 4518-4534 (2013).

37. Rose, B. E. J., Armour, K. C., Battisti, D. S., Feldl, N. \& Koll, D. D. B. The dependence of transient climate sensitivity and radiative feedbacks on the spatial pattern of ocean heat uptake. Geophys. Res. Let. 41, 1071-1078 (2014).

38. Frey, W. R., Maroon, E. A., Pendergrass, A. G. \& Kay, J. E. Do southern ocean cloud feedbacks matter for 21st century warming? Geophysical Research Letters 44, 12,447-12,456 (2017).

39. Danabasoglu, G. et al. The community earth system model version 2 (cesm2). J. Adv. Model. 12, e2019MS001916 (2020).

40. Gettelman, A. et al. High climate sensitivity in the community earth system model version 2 (cesm2). Geophys. Res. Let. 46, 8329-8337 (2019).

41. Seland, Ø. et al. The norwegian earth system model, noresm 2 - evaluation of the cmip6 deck and historical simulations. under revision, Geosci. Model Dev. 2020, 1-68 (2020).

42. Danabasoglu, G. et al. The ccsm4 ocean component. J. Clim. 25, 1361-1389 (2012).

43. Bentsen, M., Iliack, M., Nummelin, A., Guo, C. \& Debernard, J. B. Bergen layered ocean model (blom): Description and evaluation of global ocean-sea-ice experiments. in prep. $\mathbf{n} / \mathbf{a}$, n/a (2020).

44. Frölicher, T. L. et al. Dominance of the southern ocean in anthropogenic carbon and heat uptake in cmip5 models. J. Clim. 28, 862-886 (2015).

45. Marshall, J. \& Speer, K. Closure of the meridional overturning circulation through southern ocean upwelling. Nature. Geosci. 5, 171-180 (2012).

46. Morrison, A. K., Griffies, S. M., Winton, M., Anderson, W. G. \& Sarmiento, J. L. Mechanisms of southern ocean heat uptake and transport in a global eddying climate model. J. Clim. 29, 2059-2075 (2016). 
47. Kirkman, C. H. \& Bitz, C. M. The effect of the sea ice freshwater flux on southern ocean temperatures in ccsm3: Deep-ocean warming and delayed surface warming. J. Clim. 24, 2224-2237 (2011).

48. De Lavergne, C., Palter, J. B., Galbraith, E. D., Bernardello, R. \& Marinov, I. Cessation of deep convection in the open southern ocean under anthropogenic climate change. Nature. Clim. Change. 4, 278-282 (2014).

49. Bernardello, R., Marinov, I., Palter, J. B., Galbraith, E. D. \& Sarmiento, J. L. Impact of weddell sea deep convection on natureural and anthropogenic carbon in a climate model. Geophys. Res. Let. 41, 7262-7269 (2014).

50. Ferreira, D., Marshall, J., Bitz, C. M., Solomon, S. \& Plumb, A. Antarctic ocean and sea ice response to ozone depletion: A two-time-scale problem. J. Clim. 28, 1206-1226 (2015).

51. Purich, A., Cai, W., England, M. H. \& Cowan, T. Evidence for link between modelled trends in antarctic sea ice and underestimated westerly wind changes. Nature Communications 7 (2016).

52. Haumann, F. A., Gruber, N. \& Münnich, M. Sea-ice induced southern ocean subsurface warming and surface cooling in a warming climate. AGU Advances 1, e2019AV000132 (2020).

53. Auger, M., Morrow, R., Kestenare, E., Sallée, J.-B. \& Cowley, R. Southern ocean in-situ temperature trends over 25 years emerge from interannual variability. Nat Commun 12, 514 (2021).

54. Purich, A., England, M. H., Cai, W., Sullivan, A. \& Durack, P. J. Impacts of broad-scale surface freshening of the southern ocean in a coupled climate model. J. Clim. 31, 2613-2632 (2018).

55. Rye, C. D. et al. Antarctic glacial melt as a driver of recent southern ocean climate trends. Geophys. Res. Lett. 47, e2019GL086892 (2020).

56. Heuzé, C. Antarctic bottom water and north atlantic deep water in cmip6 models. Ocean Science 17, 59-90 (2021).

57. Zhang, L., Delworth, T. L., Cooke, W. \& Yang, X. Natural variability of southern ocean convection as a driver of observed climate trends. Nature Climate Change 9, 59-65 (2019).

58. Boé, J., Hall, A. \& Qu, X. Deep ocean heat uptake as a major source of spread in transient climate change simulations. Geophysical Research Letters 36, L22701 (2009).

59. Dufresne, J.-L. \& Bony, S. An assessment of the primary sources of spread of global warming estimates from coupled atmosphere-ocean models. Journal of Climate 21, 5135 - 5144 (01 Oct. 2008). URL https://journals.ametsoc.org/view/journals/clim/ 21/19/2008jcli2239.1.xml. 
60. Rose, B. E. \& Rayborn, L. The effects of ocean heat uptake on transient climate sensitivity. Current Climate Change Reports 2, 190-201 (2016).

61. Soden, B. J. et al. Quantifying climate feedbacks using radiative kernels. J. Clim. 21, 35043520 (2008).

62. Pendergrass, A. G., Conley, A. \& Vitt, F. M. Surface and top-of-atmosphere radiative feedback kernels for cesm-cam5. Earth Syst. Sci. Data 10, 317-324 (2018).

63. Hurrell, J. W. et al. The community earth system model: A framework for collaborative research. Bull. Am. Met. Soc. 94, 1339-1360 (2013).

64. Reichler, T., Dameris, M. \& Sausen, R. Determining the tropopause height from gridded data. Geophys. Res. Lett. 30 (2003). 


\section{Figures}

a)

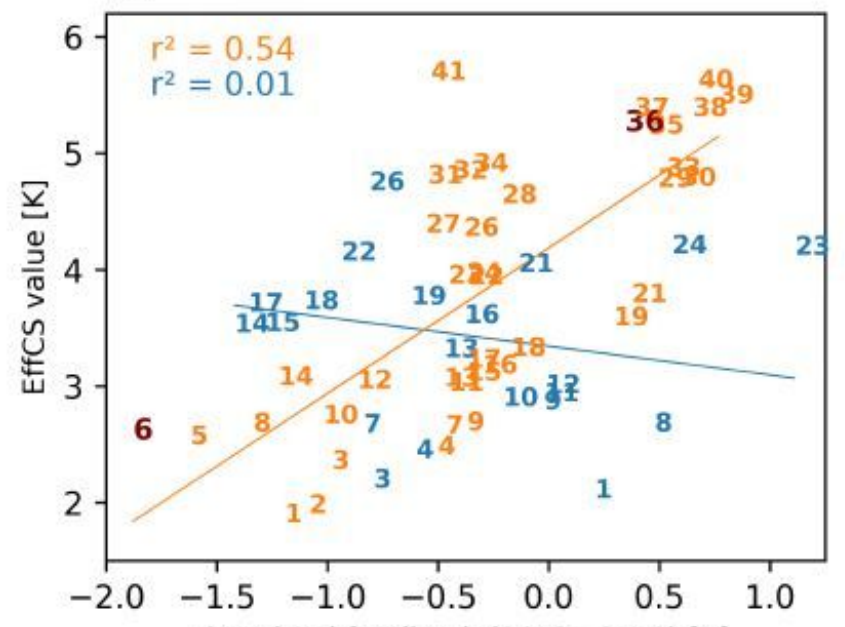

c)

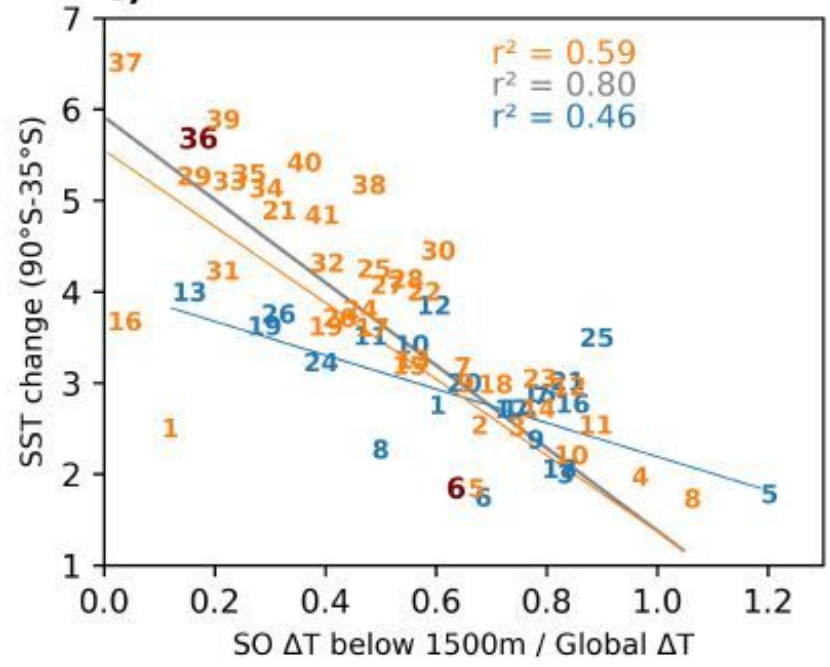

b)

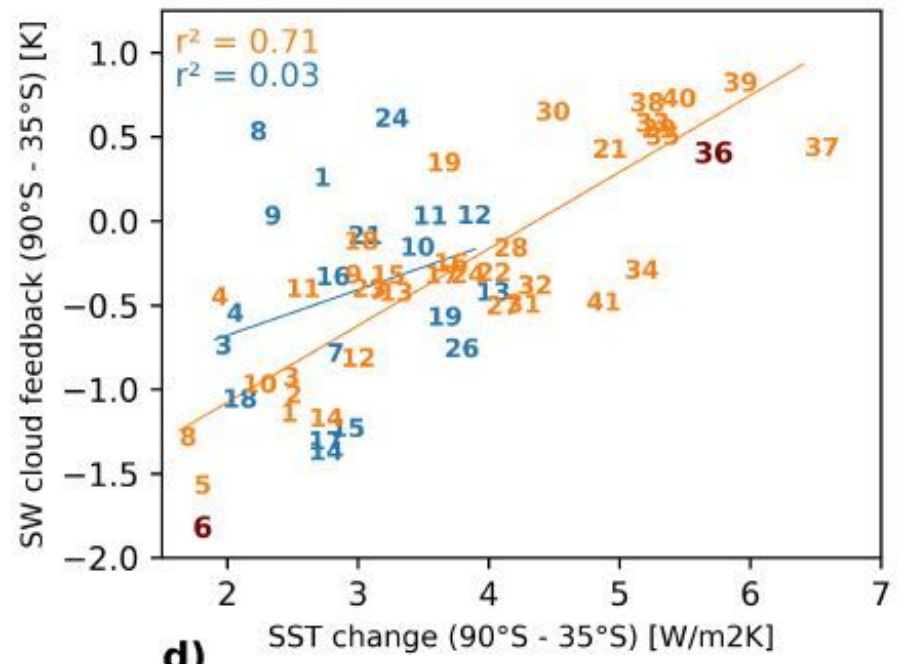

d)

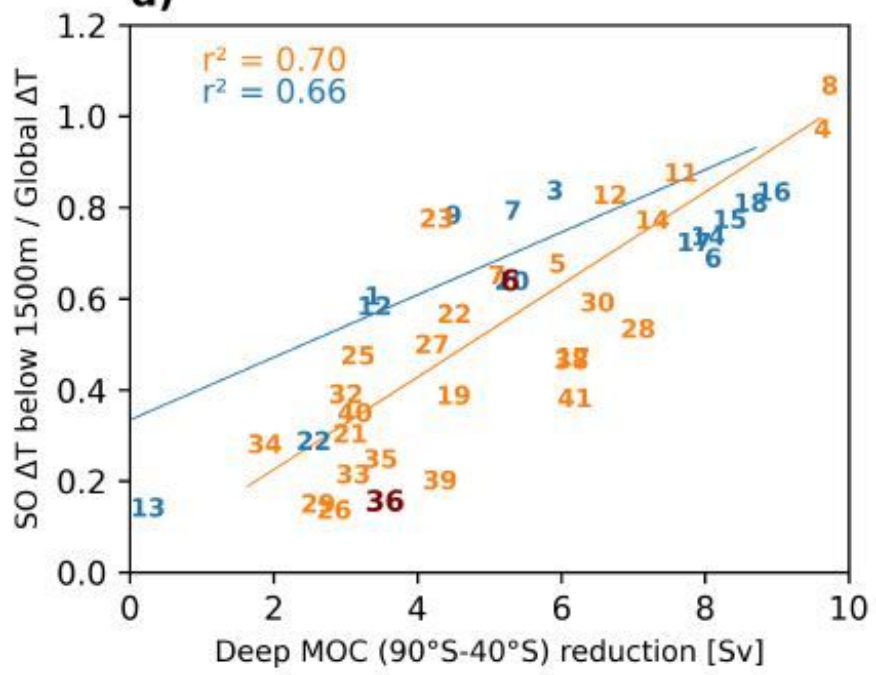

\section{Figure 1}

Correlations. Correlations applied to the CMIP5 ensemble (blue) and CMIP6 ensemble (orange). Upper row: EffCS and the SW cloud feedback south of $35^{\circ} \mathrm{S}$ (a), SW cloud feedback and SST warming south of $35^{\circ} \mathrm{S}$ (b), SST warming south of $35^{\circ} \mathrm{S}$ and the change in SO ocean temperature below $1500 \mathrm{~m}$ and south of $50^{\circ} \mathrm{S}$ relative to the change in the global ocean temperature (c), mean reduction in deep MOC south of $40^{\circ} \mathrm{S}$ and the change in SO ocean temperature below $1500 \mathrm{~m}$ and south of $50^{\circ} \mathrm{S}$ relative to the change in the global ocean temperature (d). The two CMIP6 members CESM2 (no. 36) and NorESM2-LM (no. 6) are highlighted in maroon. All models including model numbers and values are listed in Tables 3 and 4 in the supplements. 

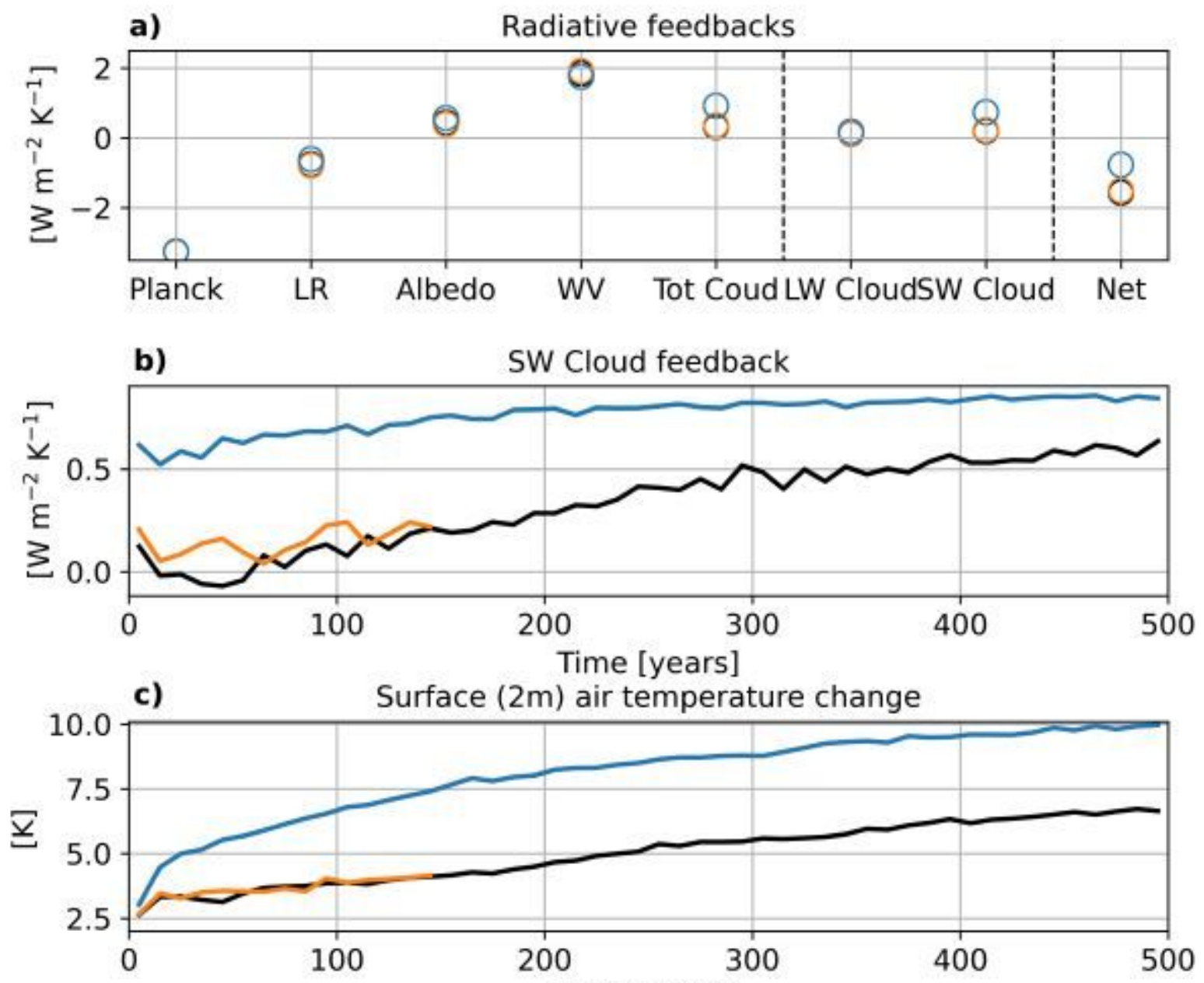

Time [years]

d) SW Cloud feedback

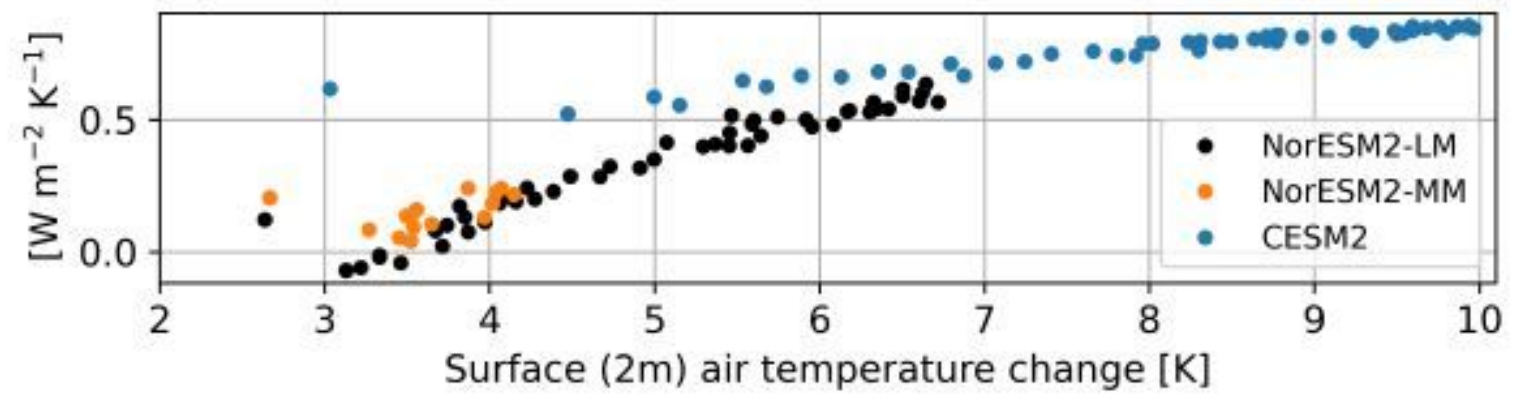

\section{Figure 2}

Radiative feedbacks. Estimates of radiative feedbacks for NorESM2-LM (black), NorESM2-MM (orange) and CESM2 (blue) calculated from abrupt- $4^{\circ} \mathrm{CO} 2 \mathrm{GHG}$-forcing simulations. The total feedback is broken down into Planck, lapse rate (LR), surface albedo, water vapour (WV) and cloud feedbacks. The cloud feedback is further broken down in contributions from SW and LW components (a). Evolution of SW cloud feedback (b) and near surface ( $2 \mathrm{~m}$ ) temperature change (c) as a function of time, and evolution of SW cloud feedback as a function of the near surface $(2 \mathrm{~m})$ air temperature change $(d)$. 

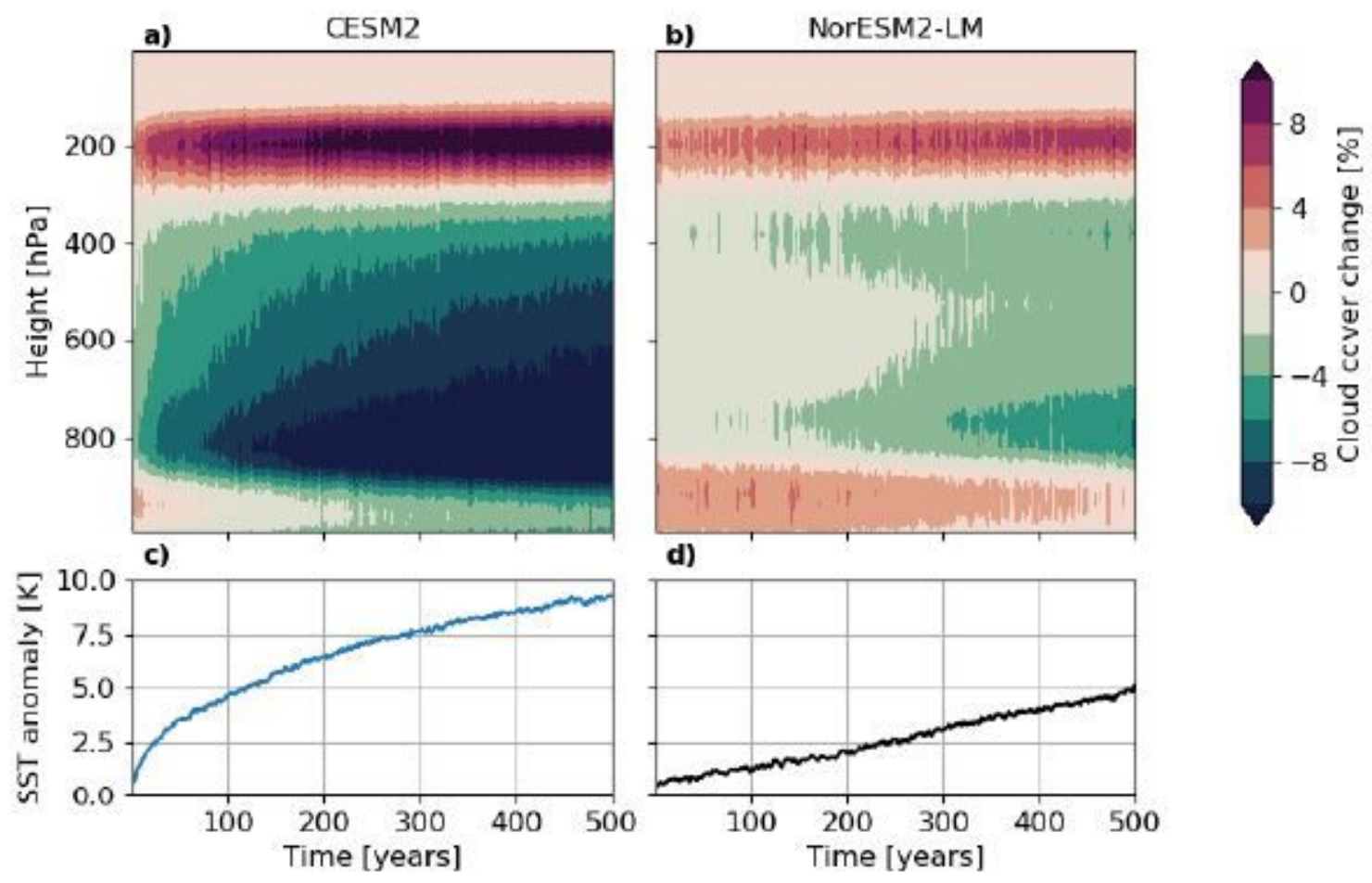

d)
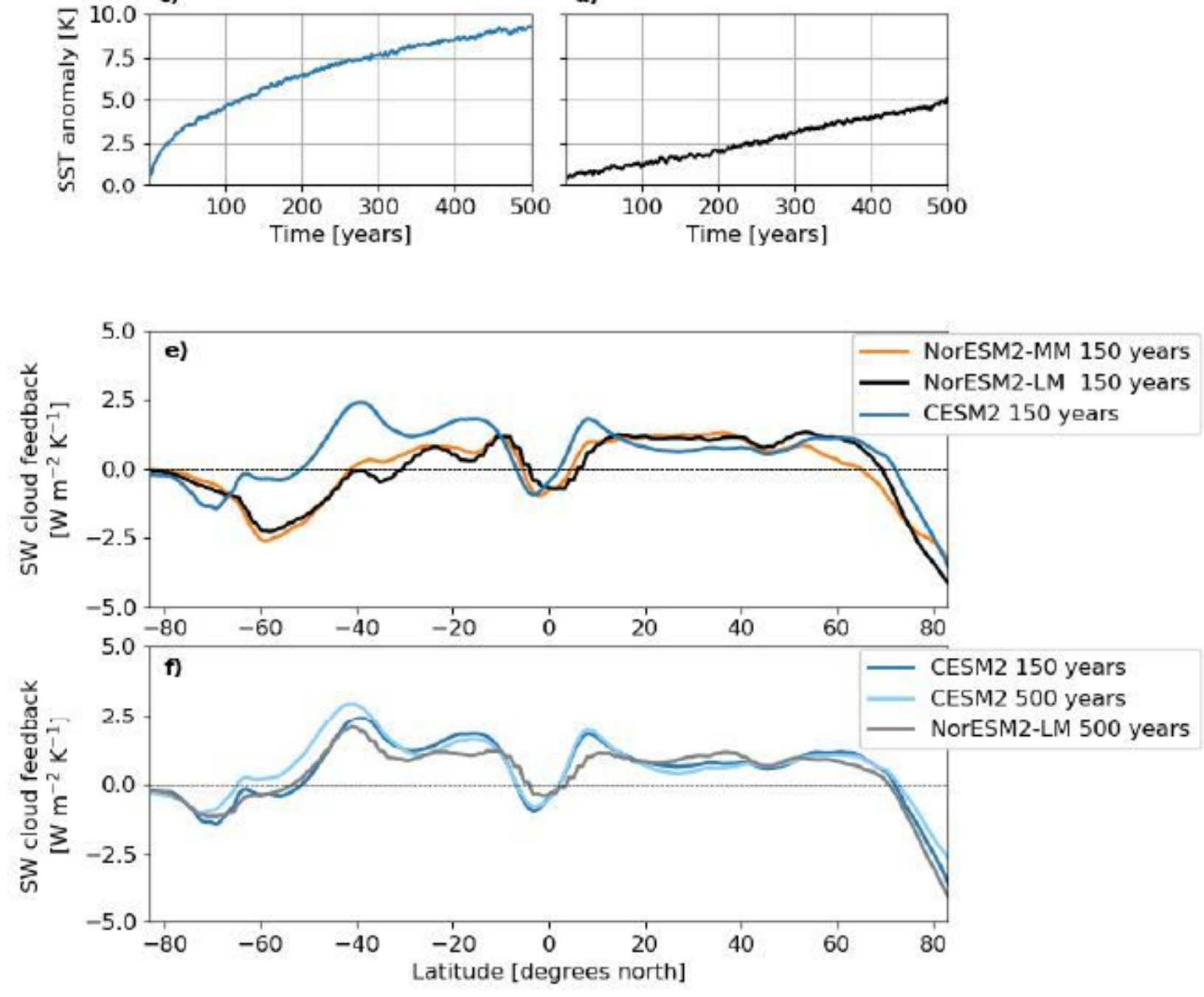

\section{Figure 3}

Cloud changes, SST warming and SW cloud feedback. Time evolution of cloud cover fraction anomaly averaged south of $35^{\circ} \mathrm{S}$ for CESM2 (a) and NorESM2-LM (b) for the first 500 years. SST anomaly for the same region and time as in a-b for CESM2 (c) and NorESM2-LM (d). Zonally averaged SW cloud feedback in NorESM2-MM (orange), NorESM2-LM (black) and CESM2 (blue) after 150 years (e) and after 
500 years in NorESM2-LM (grey), and CESM2 (light blue) (f). Also included in (f) is the SW cloud feedback from CESM2 (blue) after 150 years for comparison.
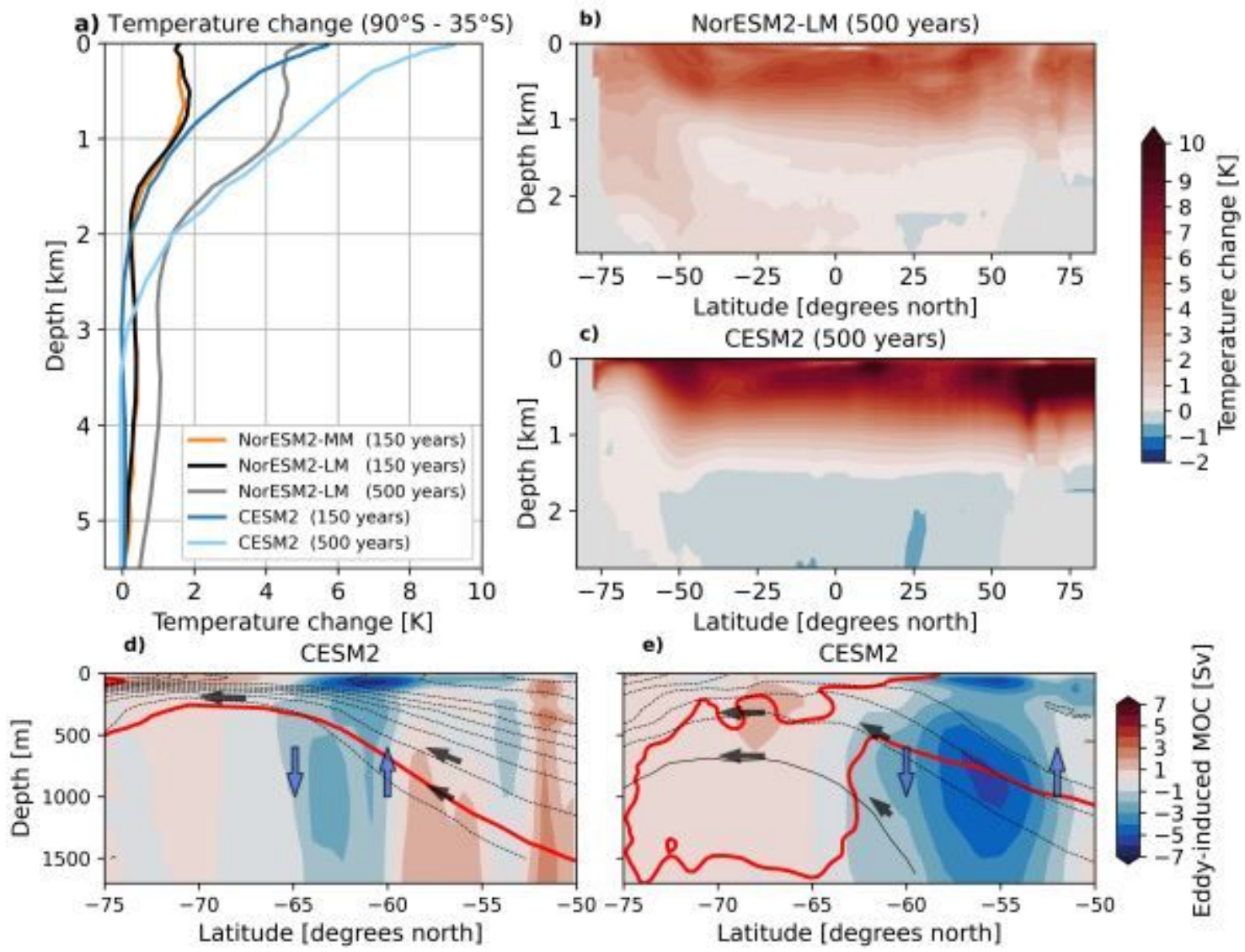

Initial SST warming (1-5 years)
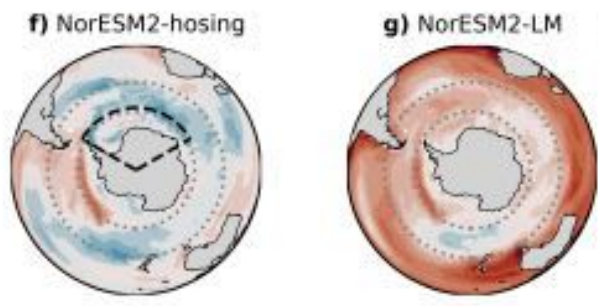

h) NorESM2-LM - NorESM2-hosing

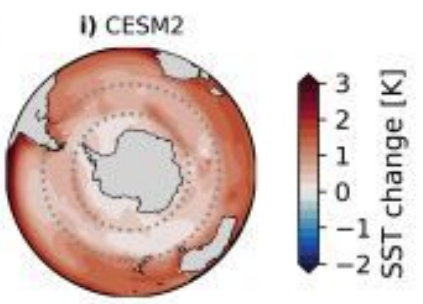

Historical SST trends (1960 - 2014)
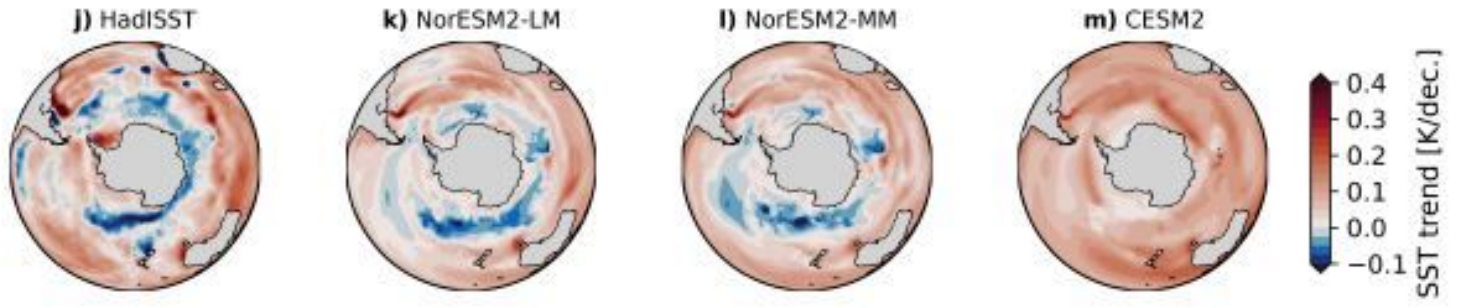

\section{Figure 4}

Ocean temperature response. Ocean temperature anomaly averaged south of $35^{\circ} \mathrm{S}$ in NorESM2-MM (orange), NorESM2-LM (black) and CESM2 (blue) after 150 years and after 500 years in NorESM2-LM (grey) and CESM2 (light blue) (a). Zonally averaged ocean temperature anomaly after 500 years in 
NorESM2-LM (b) and CESM2 (c). Response in the eddy-induced MOC to abrupt- $4^{\circ} \mathrm{CO} 2$ forcing after 150 years (shading) and in the surfaces of constant density (black, dashed lines) in CESM2 (d) and NorESM2LM (e). The black arrows indicate the anomalous along-isopycnal transport and the red contour show the $1 \mathrm{~K}$ warming. The initial (first 5 years) SST response to forcing in NorESM2-LM and CESM2 (g,i). SST anomaly to SO convection shutdown in NorESM2-LM (f). The region of freshwater forcing is indicated by the black dashed lines. SST anomaly to abrupt $-4^{\circ} \mathrm{CO} 2$ forcing (f) and to abrupt- $4^{\circ} \mathrm{CO} 2$ forcing when the response from the convection shutdown is removed ( $f$ subtracted from $\mathrm{g}$ ) (h). SST anomaly to abrupt$4^{\circ} \mathrm{CO} 2$ forcing in CESM2 (i). The grey dotted lines in e-h indicate the region with high negative SW cloud feedback bounded by $62^{\circ} \mathrm{S}$ and $45^{\circ} \mathrm{S}$ (see Fig. 2). SST trends for the period (1960-2014) from observations (HadISST, j), NorESM2-LM (k), NorESM2-MM (l) and CESM2 (m).

\section{Supplementary Files}

This is a list of supplementary files associated with this preprint. Click to download.

- supplementecs20210324.pdf 